\title{
“Nunca é agora entre nós": separações e ruturas em Explicação dos Pássaros, de António Lobo Antunes
}

\section{"Nunca é agora entre nós": Separations and Ruptures in Explicação dos Pássaros, by António Lobo Antunes}

RICARDO RATO RoDRIgues [ricardo.rato.rodrigues@uj.edu.pl] Uniwersytet Jagielloński w Krakowie, Polónia

\section{RESUMO}

Este artigo tem como objetivo explorar as diferentes dimensões do conceito de separação e rutura no romance Explicação dos Pássaros, de António Lobo Antunes. Este romance, em particular, pode ser considerado um desenvolvimento importante dentro da obra do escritor, pois marca um afastamento de sua produção literária anterior. Além disso, para lá do seu significado literário, o romance levanta também o véu do contexto histórico e sociológico do Portugal pós-revolução, com os seus conflitos e paradoxos. É abordando a maneira como o autor articula os diferentes modos de separação e conflito que o leitor pode penetrar no romance, tornando-se um participante ativo, objetivo do projeto literário Antuniano. Assim, este artigo procura dissecar as diferentes maneiras pelas quais a separação funciona como uma metáfora para o trabalho mais amplo do autor e ao mesmo tempo como uma janela para os problemas de Portugal contemporâneo.

\section{Palavras-Chave}

Lobo Antunes; separação; pós-revolução em Portugal; literatura contemporânea portuguesa

\section{Abstract}

This article aims to explore the different dimensions of the concept of separation and rupture in the novel Explicação dos Pássaros by António Lobo Antunes. This particular novel can be considered as an important development within the oeuvre of the writer as it marks a departure from his previous literary output. Moreover, besides it's literary significance, the novel also lifts the veil on the historical and sociological world of Post-Revolution Portugal, with its conflicts and paradoxes. It is by tackling the way in which the author articulates the different modes of separation and conflict that the reader can penetrate the novel, becoming an active participant, which is the aim of the Antunian literary project. Thus, this article endeavours to dissect the different ways in which separation functions as a metaphor for the wider work of the author and at the same time as a window into the problems of contemporary Portugal.

\section{KEYWORDS}

Lobo Antunes; separation; post-revolution Portugal; Portuguese contemporary literature 
Em uma das cenas iniciais do quarto romance de António Lobo Antunes, Rui S., personagem principal e narrador ocasional, lamenta o estado da sua relação com a sua mãe moribunda. "Nunca é agora entre nós, é sempre até domingo, até sexta, [...] até para o ano, mas evitamos cuidadosamente enfrentar-nos, temos medo uns dos outros, medo do que sentimos uns pelos outros [...]” (Lobo Antunes 2004: 23).

Romance de quebra (de separação) com os três anteriores, Explicação dos Pássaros marca uma rutura não só na trajetória literária do autor (separação literária), mas espelha também as fragmentações sociais que se verific(ar)am em Portugal no pós-25 de Abril (separação social) e os dilemas e conflitos individuais resultantes da necessidade de uma nova orientação do Eu, a busca necessária de uma identidade que se enquadre nas renovadas coordenadas histórico-temporais da realidade do pós-ditadura (separação individual) e o seu panorama emocional conturbado.

De facto, o romance encapsula todas estas dimensões, espelhando uma frustrante busca de uma identidade ajustada a essa nova realidade de liberdade social. Contudo, e talvez contracorrente ao espírito de esperança instaurado pela Revolução, o romance põe em evidência um certo mal-estar, uma náusea existencial resultante dessas separações, uma falta de vontade de diálogo, de entendimentos comuns e honestos confrontos. Esse "agora" que Rui S. identifica como faltando, é o ponto fulcral do qual todas as partes intervenientes parecem evitar. Assim, parecem existir apenas duas direções teleológicas as fações intervenientes parecem contemplar: o passado e o futuro, nunca o presente, o Agora que falta. Enclausurados num passado oprimido ou opressor (dependendo do quadrante social), comprometidos com uma visão utópica do futuro ou suspeitosos dessa mesma direção utópica, as forças sociais do pós-25 de Abril parecem não partilhar de uma linguagem comum e de uma conceção histórica vazia ora para uns ora para outros.

Explicação dos Pássaros é então um romance não só acerca de separações, mas acima de tudo acerca da incomunicabilidade presente nessas separações. "Assim, essa eterna falta, essa busca infinita, essa carência da linguagem, esse esvaziamento da história se faz presente na ficção do escritor português António Lobo Antunes, em seu risco constante de incomunicabilidade radical pela perda de seu destino." (Bylaardt 2012: 45-46)

\section{Separação Literária}

As preocupações literárias de Lobo Antunes até este romance de alguma forma incidiam sobre as mesmas ou semelhantes problemáticas, mas faziam-no, contudo, desde um prisma fortemente autobiográfico. É com este seu quarto romance que o autor se liberta da catarse autobiográfica e inverte o prisma do seu olhar artístico, debruçando-se não mais sobre apenas um $E$, mas agora também sobre o Outro.

Centrado na crise existencial de Rui S., o romance situa-se entre Lisboa e Aveiro, entre constantes prolepses e analepses, narrando a situação de impasse em que Rui S. se encontra, partindo para Aveiro com a sua segunda esposa (Marília), depois de uma visita ao hospital onde a sua mãe jaz, morrendo de cancro. O intuito da viagem começa por ser uma conferência, em Tomar, a que Rui e Marília deveriam assistir. Inesperadamente, Rui propõe que em vez da conferência em Tomar, ele e Marília passassem o fim-de-semana em Aveiro, numa pensão barata. No entanto, o ímpeto de Rui não é inocente: ele planeia anunciar que se quer separar de Marília. 
Já divorciado uma vez do seu primeiro casamento com uma mulher a que chama Tucha (diminutivo que indica algum escárnio), Rui S. planeia repetir o ato. Contudo, é Marília que se antecipa e anuncia a sua intenção de se separar dele. O fim de semana termina em tragédia, Marília abandona Aveiro e Rui S. comete suicídio, um ato que tem também significado simbólico como metáfora para a impossibilidade da formação de uma identidade individual e coletiva no contexto dos conflitos pós-Revolução como os percebe Lobo Antunes.

Abordando brevemente o suicídio, há-que realçar que o paradoxo inscrito neste ato é o facto de ser apenas através dele que Rui S. consegue expressar alguma liberdade individual e se libertar das diversas pressões que o assolam. O fato de ser "devorado" pelas próprias figuras normalmente associadas com liberdade não pode deixar de ser visto como um apontamento irónico. É como se o suicídio de Rui S. fosse o resultado direto da liberdade pós-ditadura, uma liberdade cujos moldes não parecem ser os ensejados pelo autor. Assim, Rui S. concretiza o seu maior ato de separação, ao rejeitar os seus laços com uma sociedade que parece apenas pedir justificações e responsabilidades, pouco ou nada reciprocando. Ecoam aqui as palavras de David Hume, que reflecte, em On Suicide:

A man who retires from life does no harm to society: he only ceases to do good [...]. All our obligations to do good to society seem to imply something reciprocal. I receive the benefits from society, and therefore ought to promote its interests; but when I withdraw myself altogether from society, can I be bound any longer? (Hume 2005: 8-9) ${ }^{1}$

Fundamental na conceção artística do autor, a tensão do individual e coletivo afigura-se como um dos aspetos mais relevantes em toda a obra do escritor e é precisamente neste romance que se encontra o incipit deste aspeto. Maria Alzira Seixo, no seu livro Os Romances de António Lobo Antunes, aponta que este romance "[...] manifesta essa oscilação ou indiferenciação de ponto de vista que tem como significação fundamental a convocação, no texto, de um sujeito plural (ou mesmo comunitário [...] e, por isso, de responsabilização colectiva pelo que acontece no romance [...]" (Seixo 2002: 102).

Antes de penetrar com mais densidade na diegética do romance, há que refletir sobre a importância deste romance como marco separativo na obra do autor. Por um lado, neste romance é possível identificar

[...] alguns traços que podemos atribuir à obra do escritor português: o risco de não exibir uma concretude, de não instaurar um diálogo efetivo com o mundo; a ausência de uma teoria que a sustente, a possibilitar respostas coerentes a perguntas certas; a insegurança de ser atemporal, a impossibilidade de se tornar algo consistente. (Bylaardt 2012:48).

Por outro lado, este é definitivamente o romance que marca uma quebra com os romances até aí publicados. Identificando os três primeiros romances como uma trilogia inserida num "ciclo", alerto para a importância de Explicação dos Pássaros como marco separativo:

1 Um homem que se retira da vida não danifica a sociedade: para apenas de fazer o bem [...]. Todas as nossas obrigações de fazer o bem na sociedade parecem implicar algo recíproco. Recebo os benefícios da sociedade e devo então promover os seus interesses; mas quando me retiro completamente dela, estarei ainda sob alguma obrigação? (Hume 2005: 8-9) 
The identification of these novels as a part of a 'cycle' takes into consideration the similarities between the novels in terms of subject, narrative person, themes and also the contrast with subsequent novels, evidenced in Explicação dos Pássaros (his fourth novel and first published in 1981), which represents a departure, a shift in narrative voice - whilst in two of the novels that constitute the trilogy the narrative voice is the first person singular (with the exception of Memória de Elefante, an occurrence that will be addressed further on), in Explicação dos Pássaros there is a shift towards third person narration. As we shall see, this is a significant shift. (Rato Rodrigues 2016: 35) ${ }^{2}$

Esta mudança significativa é também identificada por Maria Alzira Seixo, que identifica muitos pormenores deste romance (as relações familiares e afetivas, o mundo profissional em que Rui S. se insere, etc.) como marcas distintivas num processo de crescente ficcionalização. Assim, para ela, estes aspetos “[...] autonomizam-se em relação a um fundo autobiográfico determinante na obra de Lobo Antunes [...] que a partir daqui consegue uma maioridade de relação descontínua, pontual ou de intensidade mais acentuadamente ficcional [...]" (Seixo 2002: 93).

Porém, esta quebra, esta mudança, não significa um abandonar dos temas (desencanto existencial, alienação, pessimismo sobre a situação nacional) iniciados anteriormente, mas antes a sua expansão para outras vozes narrativas, indicando uma libertação narrativa da força constritora do ego para uma polifonia mais acentuada. Tal libertação, aqui separação necessária para a evolução do projeto romanesco antuniano:

[...] only manifests itself in its totality in Explicação dos Pássaros and the novels that follow it. From this work onwards, each of the novels is different; they have different narrative voices, in the majority of cases multiple, pertaining to different characters and different points of view, they grow in complexity and diversity and it becomes increasingly more difficult to discern who the narrator is. In a way, they represent successive attempts to address what was left unwritten in previous novels. (Rato Rodrigues 2016: 37) 3 $^{3}$

Também em Explicação dos Pássaros, Lobo Antunes usa processos narrativos já familiares na sua obra, em particular o monólogo interior, usado para refletir a presença de uma temporalidade difusa na consciência da personagem. Contudo, enquanto que na trilogia inicial esse monólogo interior está delimitado à consciência de um narrador singular, neste romance (e nos que se seguem) "[...] a prosa antuneana tenta constantemente atualizar os planos da memória e textualizar o tempo esvaído, projetado na plurivocalidade das personagens narradoras.” (Bilange 2007: 97)

2 A identificação destes romances como parte de um "ciclo" toma em consideração as semelhanças entre os romances em termos de sujeito, voz narrativa, temas e também o contraste com os romances subsequentes, evidenciado em Explicação dos Pássaros (o seu quarto romance, publicado em 1981), que representa uma quebra, uma mudança na voz narrativa. Enquanto que em dois dos romances que constituem a trilogia a voz narrativa é a primeira pessoa do singular (com exceção de Memória de Elefante, ocorrência que será tratada mais adiante), em Explicação dos Pássaros existe uma mudança para a terceira pessoa do singular. Como veremos, esta é uma mudança significativa. (Rato Rodrigues 2016: 35)

$3[\ldots]$ apenas se manifesta na sua totalidade em Explicação dos Pássaros e nos romances que se seguem. Desta obra para a frente, cada romance é diferente; apresentam vozes narrativas diferentes, na maioria das vezes múltipla, pertencentes a diferentes personagens e a diferentes pontos de vista, elas crescem em complexidade e diversidade, tornando-se cada vez mais difícil de discernir quem o narrador é. De certa forma, representam uma tentativa de continuar o que não foi escrito nos romances anteriores. (Rato Rodrigues 2016: 35) 
De certa forma, este é o romance que marca o divórcio de um Lobo Antunes-autor de romances preocupados em fazer uma expiação e catarse autobiográficas e um Lobo Antunes de olhar mais acutilante, virado para fora e mais atento ao Outro.

É, de certa forma, um romance-saída (embora a saída nunca seja total nem feliz). E também um romance de saídas. Diz-nos Maria Alzira Seixo: “[...] o quarto romance de Lobo Antunes, é justamente o primeiro no qual se aborda a questão da saída: a saída de Lisboa [...], a saída de cena (a parte satírica e grotesca do romance encara os dados da situação vivenciada como um espectáculo de circo [...] e a saída da existência (e do romance, através do suícidio de Rui [...]” (Seixo 2002: 95).

Para além disso, não é só no plano da obra do autor que este romance se afigura como uma separação. É então (e aqui não difere dos seus antecessores) também no plano da história da literatura portuguesa que este romance representa a continuação do divórcio entre as narrativas pré e pós- 25 de Abril. Como identifica Sara Oliveira: “A queda do regime cinquentenário em 1974, que marcou igualmente o fim tardio do império português, foi a real e também simbólica ruína das narrativas legitimadoras entre nós. A ficção portuguesa dos anos finais de 1970 testemunha essa vivência do fim da História [...]" (Oliveira 2010: 177). Assim, é fácil perceber que a obra antuniana é também ela um processo de separação, de divórcio, de quebra com um passado literário. A sua literatura faz então parte de todo um processo de desmitificação e desmantelamento das narrativas utópicas, de direita ou de esquerda, um ato de suspeição comum na literatura pós-moderna. Neste aspeto, a obra de Lobo Antunes não é pioneira (porque um pouco tardia no abordar destas questões), mas faz indubitavelmente parte do movimento de divórcio encetado pelos escritores pós-Revolução, em grande parte contribuindo para tal. No seu artigo O conto alegórico e Nova Literatura em Portugal, Sílvia Oliveira aponta precisamente a importância do contexto políticosocial na produção artística deste período:

Esta contextualização permite entender que a vivência da pós-modernidade na arte e sociedade portuguesas é contemporânea quer da esperança revolucionária anterior ao 25 de Abril de 1974, quer da desaceleração pós-revolucionária e da rápida homogeneização europeizante. [...] A pós-modernidade instalou-se em Portugal em contrapontos de luz e sombra, entre dinâmica de professado empenhamento e marcada suspeição. (Oliveira 2010: 177)

É precisamente esta "marcada suspeição" que caracteriza a obra do escritor, arraigada numa negatividade e pessimismo para o qual não parece haver solução. A epítome de tal desesperança é o ato final de Rui S.; o suicídio.

\section{Separação Social}

Entrando-se no espaço diegético do romance, percebe-se que a separação que fermenta na mente de Rui S. manifesta-se também nas suas relações sociais, espelhando os conflitos (para os quais não se afigura solução) do Portugal pós-Revolução. Rui provém de uma classe social abastada e que se percebe com boas relações com o regime ditatorial, ou pelo menos beneficiando dele. A sua situação social torna-se clara na nota do seu óbito: 
Faleceu Rui S. [...]. Contava trinta e três anos de idade. Oriundo de família bem conhecida no meio financeiro nacional e não só, frequentou sempre com razoáveis classificações o curso dos liceus, onde desde muito cedo se distinguiu pela lhaneza do trato, pela profundidade da sua inteligência e por uma cultura invulgar. (Antunes 2004: 159)

Fica claro que as origens sociais de Rui são privilegiadas, bem como a sua inteligência e pendor intelectual. Contudo, a este privilégio associa-se uma certa "rebeldia" social que o faz quebrar com a tradição familiar, gorando as expectativas de continuação do status quo da sua condição. Tal quebra rebelde leva-o a seguir caminhos profissionais e políticos distintos.

Concluído o sétimo ano, prontamente ingressou no curso de História da Faculdade de Letras, rompendo desse modo, quiçá abruptamente, com uma tradição familiar de brilhantes economistas e gestores [...]. Por esse período exerceu paralelemente corajosa actividade política (distribuindo panfletos e policopiando comunicados) [...] cargo de que viria posteriormente a demitir-se por divergência de fundo no que concerne à orientação a tomar quanto à resistência estudantil no decurso da longa noite fascista que dolorosamente atravessámos. (Antunes 2004: 159)

A rutura de Rui com a tradição familiar não se configura, porém, apenas como um ato de rebeldia de adolescente zangado com o mundo. Ao colocar Rui neste espaço de desconforto social, Lobo Antunes encapsula na personagem a sua própria visão negativa dos conflitos socias de que escreve, reafirmando, pela negatividade, a necessidade de um diálogo social mais alargado e não o extremar de posições política em que Rui se encontra inserido. "Em Explicação dos pássaros o rompimento do diálogo do Eu com a classe indica o grau da crise desencadeada por Rui S.: ao contrariar o modo de ser do grupo, o personagem reitera seu caráter de negatividade, realizando o percurso do burguês anti-burguês." (Pereira 2006: 112).

No entanto, apesar de escolhido este percurso, escolhido o caminho da "burguesia anti-burguesia", Rui parece ser, entre todos, o menos convicto da sua identidade política, o mais relutante em assumir o propósito do seu Eu. As suas dúvidas existenciais nascem, em parte, das inevitáveis pressões sociais da sua classe, aquela com a qual apesar de querer romper, exerce ainda uma pressão centrífuga inexorável. Refletindo no seu primeiro casamento falhado, com Tucha, uma mulher proveniente da mesma classe social, Rui denuncia essas mesmas pressões: "Casei-me porque gostava de ti ou porque toda a gente se casava nessa altura, as minhas irmãs, os meus primos, os amigos [...]? Pensa Casei-me porque me assaltava a ilusão de poder ser dono de qualquer coisa nem que fosse, ao menos, de mim mesmo [...]?” (Antunes 2004: 38).

A pressão capitalista do meio do qual provém, obcecada com propriedade e com "ser dono" manifesta-se assim, desta forma tão oblíqua como destruidora na psique de Rui. Contudo, ainda que se tenha conseguido libertar destas pressões e atingido um grau de liberdade emocional (embora traumática pois não é ele a propor o primeiro divórcio), Rui não consegue libertar-se do espectro da sua classe social. Esse espectro assombra a sua próxima relação, com Marília, que provém de um contexto social modesto: "E no entanto, pensou ele, eras bem do meio de onde vinhas, nunca topei com pés tão grandes como os teus, de unhas achatadas e largas, semeados de gretas [...]. - A união entre pessoas de classes desiguais dá sempre bota - sentenciou a irmã [...].” (Antunes 2004: 31-32) 
Ao tentar racionalizar este desconforto, Rui parece achar culpa não no autoritarismo e conservadorismo da sua classe, mas nas suas convicções políticas e circunstâncias pessoais, ironicamente pondo a nu esses mesmos conflitos sociais de que é vitima. "Pois mas há cinco anos eu era idealista, entusiasta, um pouco pacóvio, saíra meio amachucado do casamento com a Tucha e acreditava na Revolução [...]" (Antunes 2004: 32).

Como aponta Ana Paula Arnaut, Rui S. parece não só recusar o seu próprio universo social como parece ser recusado por este:

Universo que Rui S. recusa - e que o recusa, porque todos os dissidentes são olhados de alto, como incapazes - mas do qual não consegue evadir-se, assim, por exemplo, a profissão de historiador não é escolhida "positivamente", por si mesma, mas "negativamente", como oposição ao universo paterno, que a não admite; e do mesmo modo, o outro "mundo" para onde parte, e que existe em contraste e oposição a este, é olhado com os olhos da Lapa, e também não é, portanto, assumido. (Arnaut 2009: 162)

A desilusão com a Revolução e ao mesmo tempo com os objetivos inadequados exercem um peso duplo na consciência de Rui, cuja reação é ensimesmar-se. A memória de si mesmo não pode, então, ser completamente livre, uma vez que está inevitavelmente ligada a um coletivo. A liberdade, que para si significa separação da sua classe social, tem contudo um preço.

A sua autodestruição face ao absurdo da situação em que se encontra, face à ausência de reconciliação, mas sobretudo face à falta de uma teleologia humanística não baseada em princípios ideológicos, representa a crise instaurada pela perda das coordenadas imperialísticas (no romance incorporadas na figura paternal), uma farsa desmascarada pela Revolução. A queda do regime, bem como a abertura a uma modernidade galopante aceleram os conflitos já presentes na sociedade portuguesa. O pós-25 de Abril é então um período de incerteza, de crise identificativa e simbólica. Rui S., emocionalmente ligado ao seu passado familiar, não consegue articular esta herança com a inevitável entrada na modernidade. "Metonimicamente, a crise de Rui S. identifica-se com a crise da contemporaneidade e, de modo mais específico, com as rupturas que afetam Portugal no século XX. O pai idealizado na infância esfacela-se quando contemplado à distância pelo adulto." (Pereira 2006: 124)

A distanciação em relação ao passado coletivo do país, caraterística da escrita de Lobo Antunes, é neste romance apresentada na dinâmica parental entre Rui S. e seu pai. Passado e presente (também futuro). "O Portugal Grande do passado é o pai revisto com o olhar crítico do 25 de Abril, ao mesmo tempo em que o florescimento dos cravos dependerá das atuações coerentes dos cultivadores que destituíram a ditadura." (Pereira 2006: 125)

Assim, a figura de Rui S. é duplamente trágica. Herdeiro de uma memória individual da qual se tenta demarcar e distanciar criticamente, ele é também herdeiro de uma memória (ou melhor, contra-memória) coletiva motivada não só pelos seus ideias políticos mas também humanos. Esta herança dupla não é todavia harmoniosa e afeta-o de forma punitiva.

Rui S., além do peso da memória individual, experimenta as pressões da memória coletiva. Vejamos as conseqüências da atuação dessas vertentes da memória no processo individual de busca do conhecimento. A memória coletiva que atua sobre Rui S. pode ser delineada através da classe 
a que ele pertence: a burguesia. [...] Desse modo, as tendências esquerdistas de Rui S. representam a transgressão das leis do clã, motivo pelo qual é censurado [...] (Pereira 2006: 122)

Rui encontra-se, portanto, no meio de um dilema existencial sem saída, uma vez que qualquer decisão existencial que tome tem necessariamente de esbarrar numa separação sem conciliação.

A absurda situação em que encontra, entre dois polos extremados, é espelhada pelo confronto entre o seu pai e Marília num jantar de família, que põe a nu todos os ressentimentos e tensões sociais da sociedade portuguesa da altura:

- Por que não estudar a revolução comunista de Abril de 74? - prosseguia obstinadamente o pai colando o cabelo às têmporas numa raiva crescente, - Porque não ensinar aos seus alunos como se destrói um país à custa de infantilidades e desmandos, como se dá um pontapé no ultramar, como se permite aos lacaios da Rússia ladrarem em São Bento? (Antunes 2004: 126)

Neste tenso diálogo, o pai de Rui revela a sua posição conservadora, a sua desconfiança em relação às forças revolucionárias ligadas maioritariamente ao Partido Comunista. Revela aqui também uma ligação ideológica ao regime ditatorial, presente na veemente defesa do "ultramar" (que se refere às antigas colónias portuguesas).

Marília responde com ironia: “- Nacionalizaram-lhe algumas das suas empresas? - perguntou serenamente [...]. - Os estupores dos comunistas têm-no obrigado a trabalhar como contínuo?” (Antunes 2004: 127). A resposta acusatória de Marília revela por sua vez o ressentimento perante a arrogância da classe social mais rica, tentando denunciar os seus interesses pessoais e mentalidade economicista.

Assim, apesar de uma vontade de separação da sua classe social (e da sua família), podemos perceber o dilema trágico em que Rui se encontra, como nota o investigador Edimilson de Almeida Pereira:

A militância política de Rui S. vai de encontro aos ideais da burguesia, na medida em que a crítica à ditadura implica na crítica aos acordos subterrâneos firmados entre os mandatários da política e os do capital. O pai de Rui S., representante do empresariado, não descarta - na luta pelos mercados de capital - os favores acenados pela ditadura. Esta, apesar do corporativismo, necessita do apoio ideológico e econômico buscado nas parcelas especulativas da alta e média burguesia. Rui S. denuncia o jogo duplo de sua classe, anti-fascista (até o ponto em que os seus privilégios não fossem lesados), mas incapaz de oposição declarada a este regime. No percurso anti-burguês Rui S. adota a postura do intelectual de vanguarda, com olhos voltados para valores secundários na escala burguesa: a filosofia, a literatura e a poesia já não despertam o espírito de mecenas na burguesia contemporânea. Intelectual de esquerda, mas burguês de berço, Rui S. vivencia a ambigüidade peculiar da classe; a relação afetiva é o campo onde tal ambigüidade assume o aspecto trágico. Nem Tucha (burguesa) nem Marília (militante comunista) solucionam o dilema do Eu fragmentado entre dois pólos opostos. (Pereira 2006: 113) 
Para além do mais, não só Lobo Antunes nos dá conta das realidades sociais do país, como parece estar em sintonia com o panorama económico internacional da altura. Assim, em Explicação dos Pássaros

[...] encontramos a ruptura da estabilidade das formas e relações de dependência, dominação e interdependência que moldaram o crescimento económico mundial no pós-guerra (a exigência de uma «nova ordem económica internacional» consagrada, precisamente em 1974, pela Assembleia Geral dasNações Unidas, exprime-a com clareza). Esta ruptura [...] se configura como um lento esgotamento da «velha ordem» [...]. (Mateus 1985: 3).

A nível nacional, esta rutura acontece num momento histórico único para Portugal, em que várias mudanças significativas ocorrem simultaneamente, algo que transparece (e o torna urgente) em Explicação dos Pássaros.

Descolonização e fim da guerra colonial, democratização e acesso às liberdades fundamentais e desenvolvimento económico, satisfação das necessidades básicas e acesso a modelos de consumo mais modernos constituem em 1974 aspirações generalizadas no seio da sociedade portuguesa que, no entanto, se exprimem de forma muito dispersa e contraditória, já que resultam mais da desagregação do próprio regime do que da afirmação de um novo projecto de sociedade e de um novo bloco social de poder suficientemente definidos. (Mateus 1985: 4).

As expetativas intransigentes de ambos os lados beligerantes (Marília e o pai de Rui) são inevitavelmente incompatíveis e Rui encontra-se no meio deste dilema sem saída, vendo também as suas expetativas e esperanças goradas. Rui S., com o seu suicídio, parece incorporar a realidade coletiva portuguesa, destinada a ver as suas esperanças e anseios de progressos bloqueados pelas limitações do pós-Revolução. O investigador Augusto Mateus sublinha esse aspeto no seu artigo 25 de Abril, transição política e crise económica: que desafios dez anos depois?:

O fosso existente entre as potencialidades (e as exigências) de transformação da sociedade portuguesa e as capacidades internas disponíveis (dos diferentes agentes, das diferentes organizações e das diferentes classes e grupos sociais), que se veio a constituir, ao longo dos anos, num dos principais instrumentos de limitação do alcance da transição aberta pelo 25 de Abril, é particularmente identificável no terreno das realidades económicas: dez anos depois, o desenvolvimento económico português continua à espera de uma perspectiva estratégica e de uma realidade prática capazes [...]. (Mateus 1985: 4)

\section{Separação Individual}

Há ainda outro aspeto a considerar em relação ao tema da separação neste quarto romance de António Lobo Antunes: a individualidade.

Na maioria dos seus romances, a busca da individualidade é uma constante e em a Explicação dos Pássaros, essa busca configura-se ainda mais urgente, dadas as múltiplas separações que aqui já analisámos. A crise coletiva (e a кpíøıc, krisis, autoral no sentido de decisão) manifesta-se com maior amplitude na crise individual de Rui S. 
Então, “[...] é possível dizer que ao espírito de crise que afeta o social corresponde o vigor de uma literatura que busca os próprios caminhos, seja revendo os fatos que transformaram a vida nacional, seja escavando nos porões da individualidade os sinais trágicos de um processo de fragmentação do sujeito" (Pereira 2006: 110).

A crise identitária de Rui S. começa pelo esforço consciente de se separar mentalmente do seu pai, no qual, no entanto, ainda busca algum protetor afeto ao pedir-lhe que lhe "explique os pássaros". Contudo, tal separação afigura-se dolorosa, na medida em que é de certa forma um ato de libertação contra uma opressão paternal castradora. "Nunca me deixaste sequer revoltar-me, ir até ao fim das minhas zangas: a tua sombra enorme, tutelar e autoritária, castrantemente protegia-me [...]" (Antunes 2004: 59).

A sombra autoritária do seu pai, metonimicamente associada ao espetro de Salazar, não lhe permite um encontrar de significado e é neste falhanço em tal busca que ele encontra o significado da sua própria existência, fazendo da antagónica separação a sua forma de existir, a identidade do seu Eu: "[...] e foi a partir de aí que decidi ir para Letras, ser professor, recusar a empresa, deixar de usar gravata, ensinar estruturalismo, teoria da literatura, poesia francesa ou outras inutilidades aberrantes" (Antunes 2004: 59).

O seu desejo gorado de encontrar conforto existencial na figura paterna é tornado ainda mais doloroso pelo facto de o pai não ver nele mérito para prosseguir a linhagem e manutenção do sua condição:

His desire to mimic his father, to learn how to shout and tell everyone to shut up, to be able to explain things to his own sons, is blocked by the overriding burden of his father's disowning of him. Most significantly, it is an act of disowning that excludes Rui from a cross-generational transfer of capital. (Rothwell 2011: 93) ${ }^{4}$

A importância simbólica desta exclusão para o universo da escrita antuniana revela uma preocupação que irá sempre acompanhar a escrita do autor, tornando-se num dos temas recorrentes na sua obra. A tensão entre memória coletiva e memória individual, em que a memória individual luta para não ser excluída, aparece-nos uma vez mais (como já nos tinha aparecido em romances anteriores), mas desta vez dispensando os contornos autobiográficos.

Edimilson Pereira, no seu artigo O exílio em casa: uma leitura de Explicação dos pássaros, de António Lobo Antunes, aponta: "Na ficção de Lobo Antunes observamos esse aspecto, quando a narrativa do Eu agride a narrativa do grupo, quando a memória do Eu é intencionalmente excluída da memória coletiva" (Pereira 2006: 118). A continuação quase obsessiva deste tema abre a porta para uma característica fundamental para a interpretação da escrita do autor e para a sua relevância literária. Embora inserido no período pós-moderno, o autor apresenta uma preocupação maior para com a problemática "grande-narrativa" portuguesa, posicionando a sua produção literária como uma "contra-narrativa" alicerçada na individualidade para desmantelar a repressiva herança histórica dessa mesma narrativa. Pós-modernista relutante, Lobo Antunes apresenta ele próprio uma "grande-narrativa" que se escreve do avesso; uma escrita de falhanços, de mal-estar,

4 O seu desejo de imitar o seu pai, de aprender a gritar de forma a calar toda a gente, de ser capaz de explicar coisas aos seus próprios filhos, está bloqueado pelo pesado fardo de ter sido deserdado pelo seu pai. Significativamente, é um ato que exclui Rui de uma transferência de capital transgeracional. (Rothwell 2011: 93) 
de infelicidade, de miséria pessoal e de pessimismo extremo. Assim, a "grande narrativa" de Lobo Antunes tem como grande fio condutor a oposição dicotómica destas duas memórias; a coletiva e a individual:

A memória individual desarma os artifícios da memória coletiva. O retornado de guerra luta contra o esquecimento. Ao contrário dos barões assinalados, seu peito regressa mutilado, com o novo sinal da fragmentação, da derrocada. A violência resgatada pela memória em Lobo Antunes impossibilita a existência do passado como local do prazer perdido. Em África ou na infância, o Eu experimentou o peso da repressão, isto é, as forças da pátria salazarista e o formalismo da autoridade familiar, respectivamente. (Pereira 2006: 119)

Existe, então, também, uma separação consciente entre narrativas. Em centrar-se em narrativas individualizadas, Lobo Antunes separa-se dos seus contemporâneos não por se preocupar menos com o coletivo, mas por ir mais longe na exploração do individual. O pendor psicológico da sua escrita parece incentivar um auto-escrutínio por parte do leitor, que se vê tentado a separar-se do seu próprio Eu. Assim, as memórias ficcionais evocadas nos seus romances, plenas de negatividade e sem nostalgia, potenciam um mal-estar existencial no leitor, que se vê confrontado com fantasmas próprios mas também alheios: "O entendimento da ficção de Lobo Antunes tem de considerar, necessariamente, a abordagem da memória como motor da narrativa. A concepção do mal-estar, enquanto a presença do passado no presente, só é possível na medida em que se considera a memória como operadora desse encontro." (Pereira 2006: 117)

Tudo isto se encontra espelhado na personagem de Rui S., que também sofre uma rutura no seu Ego. Por se encontrar dividido na tentativa de fazer coexistir a sua existência interior com a sua existência familiar, a sua personalidade acaba por se fragmentar, muito por culpa do momento histórico-politico, mas ainda mais pela inabilidade (ou relutância) do coletivo perante o individual. Como assinalado por Almeida Pereira: "Os espaços ocupados por Rui S. e a família refletem as ideologias que os separam, ou seja, ao despojamento militante da esquerda opõe-se o sentido da autoconservação burguesa. O que é importante assinalar é a questão da identidade individual que se conserva para o clã e se dilui para Rui S.” (Pereira 2006: 116)

Esta diluição da individualidade de Rui S. abre espaço para a penetração do leitor no texto, algo que encontramos em toda a obra do autor. Ao não apresentar saída para a personagem, ao não resolver os seus conflitos de outra forma que não o suicídio, Lobo Antunes entrega a chave ao leitor. Desta forma, a anulação de Rui S. é a inauguração do leitor como participante ativo da escrita. Paradoxalmente, as separações e ruturas presentes ao longo da obra, em particular a rutura Eu-Eu que leva ao desespero e suicídio de Rui S., são fundamentalmente necessárias para a presença do leitor. Diz-nos Edimilson Pereira:

O espaço do romance, que abriga a escrita, não é suficiente para esclarecer o mal-estar do Eu. A personalidade fragmentária de Rui S. desafia a capacidade divinatória do leitor e impõe-se como organizadora de uma anti-narrativa. Quando Rui S. narra, suas palavras dizem para não dizer, revelam para não revelar, induzindo a explicação dos pássaros a um processo de não esclarecimento. A sedução do título do romance termina em decepção, uma vez que, morto, Rui S. interrompe os diálogos e não aponta a saída dos labirintos estabelecidos por sua anti-narrativa. (Pereira 2006: 110) 
Ainda que a presença da palavra "explicação" no título do romance possa frustrar certos leitores que, incautos, a busquem no próprio texto, a anti-narrativa antunina tem como objetivo que em vez de procurar no espaço do texto alguma linha explicativa, o autor busque em si mesmo, no seu íntimo, com a chave que o autor lhe deu. Em si, isto é também uma forma de separação entre texto e leitor. E é talvez esta separação que faz a escrita de Lobo Antunes tão urgente.

No entanto, o leitor parece compartilhar da mesma frustração da personagem principal, que vê a sua busca por algum tipo de explicação gorada com o esboroamento da possibilidade de felicidade que parece desaparecer juntamente com a sua infância. Maria Alzira Seixo reflete também neste tópico: "[...] tal felicidade é contrariada pelo futuro dessa infância [...] e justifica em pate o mal-estar que vai acompanhar perenemente a personagem [...] aliando o irrisório e a inutilidade a uma vertigem que é sua marca patológica também frequente” (Seixo 2002: 97).

No romance, Rui S. enceta uma mímica dessa mesma procura de significado, embora infrutífera. Ao tentar buscar sentido na figura paterna e ver a sua tentativa falhar, Rui S. espelha uma memória coletiva (Portugal) tentado encontrar o seu sentido no passado. No romance, Lobo Antunes utiliza simbolicamente dois elementos para ilustrar o processo de busca e de subsequente falhanço; os pássaros e o episódio de canibalismo em que a família consome a carne de Rui S. Como aponta Philip Rothwell, "[...] in the novel, birds always represent a meaning that is sought from a father but never ceded. Their ingestion of Rui's flesh is a metaphoric gesture representing Rui's unfulfilled search for meaning. It is a search that destroys him. Literally, the failure to satisfy his need for meaning consumes his flesh (Rothwell 2011: 91) 5

$\mathrm{O}$ ato antropófago tem, então, essa importância de obliterar o sujeito face a uma realidade da qual não gosta e à qual não consegue (ou se recusa) a pertencer. Essa anulação marca também (simbolicamente) o fim da paternidade, pois Rui S. morre sem deixar filhos: "Rui's death is as much a final recognition of the end of paternity as an act of self-obliteration" (Rothwell 2011: 91) .

Sendo a questão paternal de fulcral importância para a obra de Lobo Antunes, este aspeto é significativo. Ao deixar a sua personagem sem descendentes, o autor parece ancorar-se numa recusa de participar na realidade do presente da mesma forma. Rui S., não encontrando alternativa viável para uma coexistência pacífica entre as partes do conflito, um assumir de culpas por parte dos opressores ou uma amenização do rancor por parte dos oprimidos, resolve ausentar-se, via suicídio, da responsabilidade de participação em tal realidade, não deixando nenhum herdeiro que possa continuar a sua linha. De certa forma, este é o seu triunfo final, a sua separação e rutura finais, que lhe permitem transferir a responsabilidade crítica para outros, incumbindo precisamente o leitor dessa tarefa.

\section{Nunca é agora entre nós}

Em jeito de conclusão, resta considerar o romance de uma forma mais sumária. Romance de separações e de ruturas, Explicação dos Pássaros é também um romance que impulsiona a escrita do

$5[\ldots]$ no romance, os pássaros representam sempre um significado que se busca no pai mas que nunca se alcança. A ingestão da carne de Rui é um gesto metafórico que representa a busca fútil de sentido. É uma busca que o destrói. Literalmente, o falhanço de satisfazer a sua necessidade de significado consome a sua carne. (Rothwell 2011: 91).

6 A morte de Rui é tanto um ato de reconhecimento final do final da paternidade como um ato de auto-obliteração. (Rothwell 2011: 91) 
autor para fora da sua dimensão autobiográfica, sem, no entanto, se descaracterizar. A focalização na problemática da memória (entre outras) representa uma continuação e uma estratégia literária que fornece ao leitor algumas pistas para a mundividência Antuniana.

Em Explicação dos Pássaros reitera-se o papel desempenhado pela memória nos demais romances de Antunes. O conteúdo recuperado fala da infância como o tempo ideal e ressalta paradoxalmente as fraturas que o atingiram. O retorno de Rui S. consiste numa paráfrase do périplo proustiano, só que, já agora, revelando desde a primeira hora, a fragmentação, a angústia e o desespero da individualidade. (Pereira 2006: 120)

Contudo, a singular importância deste romance (e ainda que não se destaque como obra maior no conjunto de romances do autor) é a urgência como coloca em relevo a necessidade de diálogo, a necessidade de aproximações sociais, a necessidade de, embora processo penoso, se focar no presente, na realidade comum entre todos os participantes de uma determinada sociedade, seja a nível político, social ou afetivo. Nesse agora que há entre nós.

\section{Referências bibliográficas}

Almeida Pereira, E. de (2006). O exílio em casa: uma leitura de Explicação dos pássaros, de António Lobo Antunes. Ipotesi, Juiz de Fora, 10, 1, 109-127.

Antunes, A. L. (2004). Explicação dos Pássaros. Lisboa: Dom Quixote.

Arnaut, A. P. (2009). António Lobo Antunes. Lisboa: Edições 70.

Bilange Azevedo, E. M. (2007). Brincadeiras com o tempo na construção do áspero humor de Lobo Antunes. São Paulo: Universidade de São Paulo (Tese Doutoral)

Bylaardt, C. O. (2012). A poética da negatividade na escritura de Lobo Antunes. Convergência Lusíada, 28, 44-54.

Hume, D. (2005). On Suicide. London: Penguin Books-Great Ideas.

Mateus, A. (1985). 25 de Abril, transição política e crise económica: que desafios dez anos depois? Revista Crítica de Ciências Sociais, 15/16/17, 281-300.

Oliveira, S. A. (2010). O conto alegórico e Nova Literatura em Portugal. Hispania, 93, 2, 177-186.

Rodrigues, R. R. (2016). A silent scream: trauma and madness in the early works of António Lobo Antunes. Nottingham: University of Nottingham (Tese Doutoral).

Rothwell, P. (2011). The demise of paternal meaning in Explicação dos Pássaros. In V. K. Mendes (ed.), Facts and Fictions of António Lobo Antunes (pp. 89-96), Dartmouth: Tagus Press, University of Massachusetts Dartmouth.

Seixo, M. A. (2002). Os Romances de António Lobo Antunes. Lisboa: Dom Quixote. 
